\title{
Multi detector computerized tomography scans aid in the staging of Head and Neck cancers
}

\author{
Sigbeku Opeyemi', Kolude Bamidele ${ }^{1}$, Adeniji-Sofoluwe Adenike ${ }^{2}$, Adeosun Aderemi ${ }^{3}$ \\ ${ }^{1}$ Dept of Oral Pathology, University of Ibadan/University College Hospital \\ ${ }^{2}$ Dept of Radiology, University of Ibadan/University College Hospital \\ ${ }^{3}$ Dept of Otorhinolaryngology, University of Ibadan/University College Hospital
}

\begin{abstract}
Introduction/Objectives: To assess the efficacy and correlation of MDCT scans in the clinical staging of patients with HNCs prior to therapeutic intervention. Methodology: Thirty-four HNCs were studied according to the 2005 WHO. Clinical AJCC 6th edition \& radiological staging. Results: 14 Squamous Cell Carcinoma (SCC 41.2\%) mean age 49.4 + 14.7 years, 13 Nasopharyngeal Carcinoma (NPC $38.2 \%$ ) mean age $37.1+20.5$ years, 3 Odontogenic Carcinoma (ODC $8.8 \%$ made up of 2 cases ameloblastic carcinoma $5.9 \%$ and 1 case of ameloblastic carcinosarcoma 2.9\%). Others cases were 3 Adenocarcinoma (8.8\%) and 1 Sinonasal Carcinoma NC (2.9\%). Mean age insignificant according to gender $(p=0.342)$. Sensitivity, specificity, positive \& negative predictive values and accuracy of clinical and radiological nodal involvements were: $(47.4 \% ; 80 \% ; 61.8 \% ; 75 \% ; 54.5 \%)$ \& $(78.9 \% ; 93.3 \% ; 85.3 \% ; 93.8 \% ; 77.8 \%)$ respectively. Difference between clinical and radiological stages was statistically significant $(X 2=260.8 ; p=0.01)$. There was a low but positive correlation between the clinical and radiologic stages (Pearson's correlation $r=0.6$ ). Conclusion: MDCT was significantly more accurate than clinical examination in the TNM of HNCs using AJCC/UICC TNM guidelines. Authors recommend MDCT as first line imaging technique in resource limited settings.
\end{abstract}

Keywords: Multi-detector CT, Staging, Head and Neck Cancers.

\section{Introduction}

Recent cancer estimates show that out of 14.1 million new cancer cases diagnosed annually more than 0.7 million patients suffer from head and neck cancers (HNCs) and $60 \%$ of all $\mathrm{HNCs}$ occur in developing countries ${ }^{1}$. HNCs are particularly distressing because the head and neck region constitute the most complex functional anatomy in the human body ${ }^{2}$. The stage of disease at presentation is the most important prognostic factor as early stage of presentation increase the survival rate and improves the quality

Received for publication: December 27, 2016 Accepted: July 01, 2017

Correspondence to:

Dr. Bamidele Kolude,

Dept of Oral Pathology,

Faculty of Dentistry, UCH, Ibadan. delekolude2003@yahoo.co.uk $+2348055309574$ of life in head and neck cancer because less aggressive and mutilating treatment options are offered ${ }^{3}$. In addition, early stage in HNC has up to a $60 \%$ chance of cure with local treatment alone whereas advanced stage disease have greater than $50 \%$ risk of recurrence and development of distant metastasis ${ }^{4}$. Unfortunately, most patients present with late stage of disease that requires radical treatment and often result in considerable morbidity and mortality with attending poor prognosis ${ }^{5}$.

Since the evolution of linear tomography, faster and better revelations and delineation of the extent of neoplasm and lymph nodes involvement became obvious when compared 
with the era of conventional radiography only ${ }^{6}$. The development of the helical multi detector computerized tomography (MDCT) has the advantage of faster $\mathrm{CT}$ scans with rapid acquisition of numerous thin ( 0.5 to $1 \mathrm{~mm}$ thickness $)$ images in axial, coronal and sagittal planes. Furthermore, excellent soft tissue delineation of tumor extent and reconstructed Shaded Surface display SSD of bony structures is possible and more accurate images than linear CT and conventional spiral CT are obtainable?

Tumor volume, lymph node infiltration distant metastases are the most important factors that influence the therapeutic approach and the prognosis of the patient with $\mathrm{HNC}^{5,8}$. Exact tumor staging is necessary for treatment planning, leading to reduced postoperative morbidity and tumor recurrence-associated mortality ${ }^{9}$. Sub mucosal extension cannot be sufficiently assessed by endoscopy and physical examination but can be evaluated with magnetic resonance imaging MRI and CT to a lesser extent ${ }^{10,11}$. Clinical examination alone frequently underestimates the extent of disease. MDCT technology is capable of acquiring high-resolution (sub millimeter) studies in less than 20 seconds, although axial images with a slice thickness of $3-5 \mathrm{~mm}$ were previously advocated in various imaging protocols. Thick slice thickness reduces resolution and makes multi-planar reformation MPR sub-optimal. When overlapping images are reconstructed from raw data with a nominal slice thickness of $0.5-1.25 \mathrm{~mm}$, (MPR) images of the tumor can be viewed interactively in any arbitrarily chosen imaging plane ${ }^{12}$.

Due to better delineation of bony extent and lymph node evaluation by contrast enhanced, CT scan (CECT) has become an essential part of the workup of HNCs patients. The present study is an assessment of the efficacy and correlation of MDCT scan in the evaluation and as an adjunct to clinical staging of patients with HNCs prior to therapeutic intervention.

Rationale for the study: The study aims to assess the efficacy of MDCT as an efficient low-cost 3D imaging technique for the evaluation of HNCs in a low economic resource setting where MRI and PET-CT are not affordable and readily available.

\section{Materials and Methodology}

A two-year study that, included 34 patients with histological diagnosis of HNC according to the 2005 WHO criteria for Head and Neck tumors ${ }^{13}$. Tumors at presentation were staged clinically according to $6^{\text {th }}$ edition of American Joint Committee on Cancer AJCC classification (AJCC, 2002) ${ }^{14}$ for head and neck sites which featured some improvements on the 5 th edition ${ }^{15}$. These improvements were in (a) uniform description of advanced tumors whereby T4 lesions were divided into T4a (resectable) and T4b (unresectable) and (b) Advanced stage diseases in patients were further assigned into three categories. The new categories were Stage IVA (advanced resectable disease); Stage IVB (advanced unresectable disease); and Stage IVC (advanced distant metastatic disease).

The 6th edition of AJCC guidelines for clinical TNM staging include "collaborative staging" aimed at increased accuracy of diagnostic test by the use of newer clinical and radiologic diagnostic techniques. Techniques such as MDCT scan, MRI, Positron Emission Tomography PET or PET-CT may result in the assignment of a higher clinical stage

Authors envisage that the advantage of this forward step in AJCC guideline will result in better patient stratification for appropriate therapy and better report of treatment outcome.

A 64-slice Toshiba Aquillon MDCT machine was used to acquire the images of all enrolled patients and MPR images of the tumor were viewed interactively in all imaging plane with radiological staging performed according to Madison et al. ${ }^{16}$ (1998).

Patients with incomplete radiographic images, incomplete data for clinical staging of head and neck cancer, lack or inconclusive histological findings, non-consenting patients and patients with primary tumors of the brain, eye, thyroid and salivary glands were excluded from the study.

Data was analyzed using version 21 software of IBM statistical package for social sciences (SPSS-21). Proportional distributions of various clinical and radiological stages were expressed as percentages and compared using chi-square statistics. Correlation of individual histological and radiological stages was conducted using Pearson's correlation statistics. Significant level was set at $\mathrm{p}<0.05$. Ethical clearance was obtained. (UI/ $\mathrm{EC} / 12 / 0238)$

\section{Results}

A total of 34 cases of head and neck cancers were enrolled in the present study. Among these, 21 were male (61.8\%) while 13 were female $(38.2 \%)$ giving a male to female ratio of 1.6:1 and the overall mean age was $42.9+17$. 1years. The mean ages according to gender were $45.1+15.7$ for males and $39.2+19.5$ for females; there was no statistically significant difference in the mean ages according to gender $(p=0.342)$.

The histology and site distribution (ICDO-9)17 of enrolled $\mathrm{HNC}$ cases are as depicted in table 1 .

More squamous cell carcinoma cases occurred among females $(69.2 \%)$ while majority of the nasopharyngeal carcinoma cases occurred among males (76.9\%). The four nasal malignancies occurred in males, two of the odontogenic carcinomas cases were males but the third was a female. There was no significant difference in the site distribution of HNC according to gender $\left(\mathrm{X}^{2}=8.1, \mathrm{p}=0.524\right)$.

Among the SCC group, the most common histological type was the keratinizing $(\mathrm{K})$ type which occurred most frequently at three sites; the maxillary sinuses see comment above $(35.7 \%)$, paranasal sinuses $(21.4 \%)$ and the pharynx $(21.4 \%)$. The most common histological type in the NPC group was the Nonkeratinizing $(\mathrm{N}-\mathrm{K})$ variety (Table 1$)$

The clinical staging revealed that a minority of the tumors $(47 \%)$ were less than $6 \mathrm{~cm}$ in diameter at the time of clinical presentation, among this group, $8.8 \%$ were T2 tumors while the remaining cases were T3 tumors (38.2\%). However, majority $(53 \%)$ of the HNCs cases were T4 clinical tumors which comprised of $47.1 \% \mathrm{~T} 4 \mathrm{a}$ tumors and $5.9 \%$ of $\mathrm{T} 4 \mathrm{~b}$ tumors.

Clinically, more than half $(55.9 \%)$ of the HNCs cases were $\mathrm{N} 0$ while $23.5 \%$ were $\mathrm{N} 1,8.8 \%$ of the cases were $\mathrm{N} 2 \mathrm{a}$ but there was no clinical tumor case of N2b or N2c. Approximately 
$3.0 \% 2.9 \%$ of the tumor cases were assessed clinically as N3. Another $8.8 \%$ of the cases were clinical NX (inaccessible lymph nodes). Furthermore, clinical assessment of metastasis revealed that $70.6 \%$ were $\mathrm{M} 0$ cases while only $8.8 \%$ were $\mathrm{M} 1$, the remaining $20.6 \%$ presented with tumor metastasis that were not discernible (MX).

Table 1 - Site distribution of HNCs according to histological types.

\begin{tabular}{|c|c|c|c|c|c|c|c|c|c|c|c|c|c|}
\hline \multirow[b]{3}{*}{ TUMOUR SITES } & \multirow{3}{*}{$\begin{array}{l}\text { 山् } \\
\text { 음 } \\
\text { 음 }\end{array}$} & \multicolumn{12}{|c|}{ HISTOLOGICAL TYPES OF HNCS } \\
\hline & & \multicolumn{3}{|c|}{ SCC } & \multicolumn{3}{|c|}{ NPC } & \multicolumn{3}{|c|}{ ODC } & \multirow[t]{2}{*}{ SNC } & \multirow[t]{2}{*}{$A D C$} & \multirow[t]{2}{*}{ TOTAL } \\
\hline & & $\check{x}$ & $\stackrel{y}{z}$ & 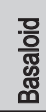 & 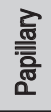 & $\underline{x}$ & $\frac{y}{z}$ & $\begin{array}{l}\text { 흥 } \\
\text { 응 } \\
\text { 局 }\end{array}$ & $\sum_{<}^{0}$ & 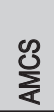 & & & \\
\hline $\begin{array}{l}\text { BASE OF THE } \\
\text { TONGUE }\end{array}$ & C01.9 & - & - & 1 & - & - & - & - & - & - & - & - & 1 \\
\hline $\begin{array}{l}\text { MAXILLARY ALVEOLAR/ } \\
\text { GUM }\end{array}$ & C03.0 & - & - & - & - & - & - & - & 1 & - & - & - & 1 \\
\hline $\begin{array}{l}\text { MANDIBULAR ALVEOLAR/ } \\
\text { GUM }\end{array}$ & C03.1 & - & - & - & - & - & - & - & 1 & - & - & - & 1 \\
\hline OROPHARYNX, & C10.9 & - & - & - & - & 1 & 3 & - & - & - & - & - & 4 \\
\hline NASOPHARYNX & C11.0 & - & - & - & - & 2 & - & 1 & - & - & - & 1 & 4 \\
\hline $\begin{array}{l}\text { LARYNGOPHARYNXI } \\
\text { HYPOPHARYNX, }\end{array}$ & C13.9 & 2 & 1 & - & - & - & - & - & - & - & - & - & 3 \\
\hline PHARYNX, & C14.0 & - & - & - & - & - & 1 & - & - & - & - & - & 1 \\
\hline NASAL CAVITY & C30.0 & 1 & 2 & - & - & 1 & 1 & - & - & - & - & 1 & 6 \\
\hline MAXILLARY SINUS & C31.0 & 2 & - & - & - & 1 & - & - & - & 1 & 1 & - & 5 \\
\hline PARANASAL SINUS & C31.9 & 2 & 2 & - & 1 & - & 2 & - & - & - & - & 1 & 8 \\
\hline TOTAL & & 7 & 5 & 1 & 1 & 5 & 7 & 1 & 2 & 1 & 1 & 3 & 34 \\
\hline
\end{tabular}

$S C C=$ Squamous cell carcinoma; $N P C=$ Nasopharyngeal carcinoma; $O D C=$ Odontogenic carcinoma $; S N C=$ Sinonasal carcinoma $A D C=A d e n o c a r c i n o m a$ ; AMC Ameloblastic carcinoma; AMCS = Ameloblastic carcinosarcoma ; $K=$ keratinizing; $n k=$ non-keratinizing.

Overall, only a minority of cases were clinical stage II and stage III tumors $(5.9 \%$ and $38.2 \%)$ respectively while the majority of the HNCs cases were stage IV tumors (55.9\%). Among the stage IV tumors, majority $(84.2 \%)$ were clinical stage IVA while $15.8 \%$ were stage IVC with metastasis to distant sites such as brain, lungs and visceral organs. There was no significant difference in the clinical stage of HNC according to sex and site $(\mathrm{p}=0.153$ KruskalWallis Non-parametric Test $\& \mathrm{X}^{2}=26.6 ; \mathrm{p}=0.49$ respectively)

MDCT imaging also revealed that a minority of the head and neck cancers were $\mathrm{T} 3$ and $\mathrm{T} 4 \mathrm{a}(11.8 \%$ each) while the majority belong to $\mathrm{T} 4 \mathrm{~b}(76.5 \%)$ with radiological evidence of tumor invasion into vital structures and surrounding tissues. The proportional changes from clinical tumour size to radiological tumour size of HNCs cases are as shown in table 2. The clinical tumor size and the radiological tumor size showed a statistical significant difference $\left(\mathrm{X}^{2}=5.5, \mathrm{p}=0.019\right)$ and a low correlation (Pearson's correlation $r=0.498$ ).

MDCT showed only a minority $(38.2 \%)$ of the cases presented as radiological N0 tumors, unlike the clinical nodal staging with majority at N0 (55.9\%). Also, $14.7 \%$ and $11.8 \%$ presented as radiological $\mathrm{N} 1$ and $\mathrm{N} 2$ a nodal involvement respectively. The only case of clinical N3 was also assessed as radiologic N3 nodal involvement. The proportional changes from clinical nodal size to radiological nodal size of HNCs cases are as shown in table 2. There was a statistical significant difference between the clinical size and the radiological size of lymph nodes involvement $\left(X^{2}=53.01, p=0.000\right)$. However, there was a higher positive correlation between clinical and radiological assessment of lymph node involvement (Pearson's correlation $r=0.690$ ) when compared with the correlation of clinical and radiologic tumor size (Table $2 \&$ figure 1). The sensitivity, specificity, positive \& negative predictive values and accuracy of clinical and radiological nodal involvements are as shown in table 3 .

Sixty two percent $61.8 \%$ of cases had radiologic assessment as M0 while $38.2 \%$ had metastasis to distant sites (M1). However, unlike the clinical tumor assessment that presented with some cases of indiscernible metastasis to distant site $(\mathrm{Mx}=20.6 \%)$, there was no tumor case of indiscernible distant metastasis with MDCT imaging because the clinical cases of MX were either regarded as M0 $(5.9 \%)$ or upgraded to M1 (14.7\%) (Table 2). There was a statistical significant difference between the clinical assessment and the radiological assessment of metastasis $\left(X^{2}=11.19, p=0.004\right)$. An inverse correlation between clinical metastasis and radiologic metastasis to distant site was observed (Pearson's correlation $r$ $=-0.054)$.

Most of the clinical stages II, III \& IV cases were upgraded to higher radiological stages as shown in table 4. There was a weak but positive correlation (Pearson's correlation $r=0.6$, Figure 2k) with statistically significant difference between the clinical stages and radiological stages of head and neck cancers cases $\left(X^{2}=260.8 \quad p=0.01\right)$.

There was a significant difference in the final clinical and radiological staging of HNCs in this study $\left(\mathrm{X}^{2}=270.79 ; \mathrm{p}=\right.$ $0.00)$ but there was no significant difference in the radiological stages of HNC according to sex and site. $(\mathrm{p}=0.445$ Kruskal-Wallis Non-parametric Test; $\mathrm{X}^{2}=33.8 ; \mathrm{p}=0.17$ respectively). 
Table 2 - The relationship between clinical TNM and radiological TNM.

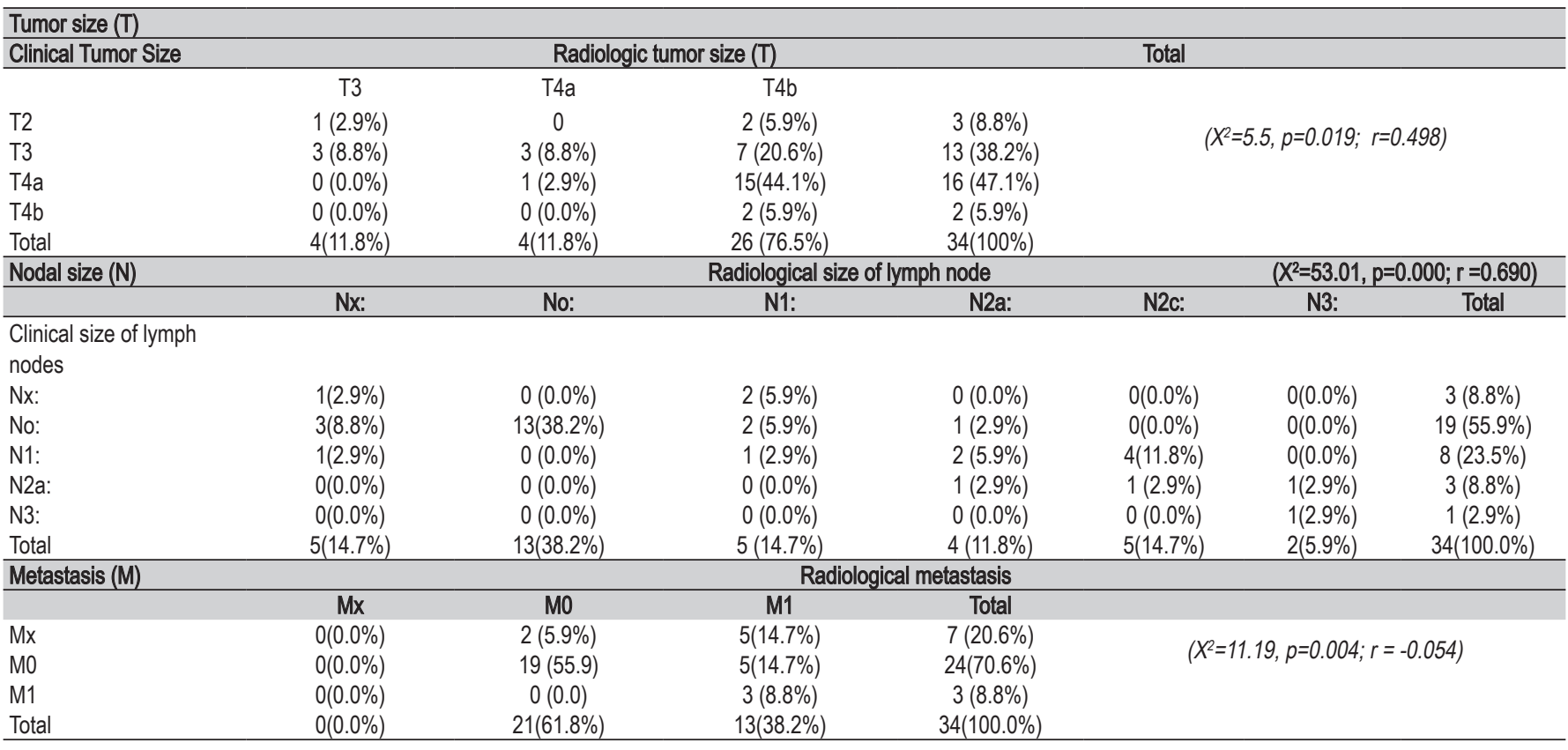

Table 3 - Comparison of the accuracy of Clinical and MDCT detection of nodal involvement.

\begin{tabular}{|c|c|c|c|c|c|}
\hline \multicolumn{6}{|c|}{ Comparison of Clinical and Histological results } \\
\hline \multicolumn{6}{|c|}{ HISTOLOGY } \\
\hline CLINICAL & Positive & Negative & Total & & \\
\hline Positive & 9 & 3 & 12 & & \\
\hline Negative & 10 & 12 & 22 & & \\
\hline Total & 19 & 15 & 34 & & \\
\hline \multicolumn{6}{|c|}{ Comparison of MDCT and Histological results } \\
\hline \multicolumn{6}{|c|}{ HISTOLOGY } \\
\hline$\overline{\mathrm{MDCT}}$ & Positive & Negative & Total & & \\
\hline Positive & 15 & 1 & 16 & & \\
\hline Negative & 4 & 14 & 18 & & \\
\hline Total & 19 & 15 & 34 & & \\
\hline \multicolumn{6}{|c|}{ Analysis of the Accuracy of Clinical versus MDCT Examination } \\
\hline Modality & Sensitivity (\%) & Specificity (\%) & Accuracy (\%) & PPV (\%) & NPV (\%) \\
\hline CLINICAL & $9 / 19(47.4 \%)$ & $12 / 15(80 \%)$ & $21 / 34(61.8 \%)$ & $9 / 12(75 \%)$ & $12 / 22(54.5 \%)$ \\
\hline MDCT & $15 / 19(78.9 \%)$ & $14 / 15(93.3 \%)$ & $29 / 34(85.3 \%)$ & $15 / 16(93.8 \%)$ & $14 / 18(77.8 \%)$ \\
\hline \multicolumn{6}{|c|}{$\overline{P P V}=$ positive predictive value,$N P V=$ negative predictive value.} \\
\hline \multirow[t]{2}{*}{ Sensitivit } & $=A /(A+C)$ & $=$ & true positives & & \\
\hline & & & true positives + false negatives & & \\
\hline \multirow[t]{2}{*}{ Specificity } & $=D /(B+D)$ & $=$ & true negatives & & \\
\hline & & & false positives + true negatives & & \\
\hline \multirow{2}{*}{ Positive predictive value } & $=A /(A+B)$ & $=$ & true positives & & \\
\hline & & & true positives + false positives & & \\
\hline \multirow[t]{2}{*}{ Negative predictive value } & $=D /(D+C)$ & $=$ & true negatives & & \\
\hline & & & true negatives + false negatives & & \\
\hline \multirow[t]{2}{*}{ Accuracy } & $=A+D$ & $=$ & true positives + true negatives & & \\
\hline & $(A+B+C$ & & all positives + all negatives & & \\
\hline
\end{tabular}

Table 4 - Relationship between the final clinical and radiological staging of HNCs.

\begin{tabular}{|c|c|c|c|c|c|c|c|c|c|c|c|}
\hline \multirow{8}{*}{ 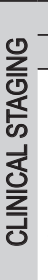 } & \multicolumn{11}{|c|}{ RADIOLOGICAL STAGING } \\
\hline & & \multicolumn{2}{|c|}{ STAGE 3} & \multicolumn{2}{|c|}{ STAGE 4A } & \multicolumn{2}{|c|}{ STAGE 4B } & \multicolumn{2}{|c|}{ STAGE 4C } & \multicolumn{2}{|c|}{ TOTAL } \\
\hline & & $\mathrm{n}$ & $\%$ & $n$ & $\%$ & $n$ & $\%$ & $n$ & $\%$ & $\mathrm{n}$ & $\%$ \\
\hline & STAGE 2 & 1 & $2.9 \%$ & 0 & $0.0 \%$ & 1 & $2.9 \%$ & 0 & $0.0 \%$ & 2 & $5.9 \%$ \\
\hline & STAGE 3 & 3 & $8.8 \%$ & 2 & $5.9 \%$ & 5 & $14.7 \%$ & 3 & $8.8 \%$ & 13 & $38.2 \%$ \\
\hline & STAGE 4A & 0 & $0.0 \%$ & 2 & $5.9 \%$ & 9 & $26.5 \%$ & 5 & $14.7 \%$ & 16 & $47.1 \%$ \\
\hline & STAGE 4C & 0 & $0.0 \%$ & 0 & $0.0 \%$ & 0 & $0.0 \%$ & 3 & $8.8 \%$ & 3 & $8.8 \%$ \\
\hline & TOTAL & 4 & $11.8 \%$ & 4 & $11.8 \%$ & 15 & $44.1 \%$ & 11 & $32.4 \%$ & 34 & $100.0 \%$ \\
\hline
\end{tabular}



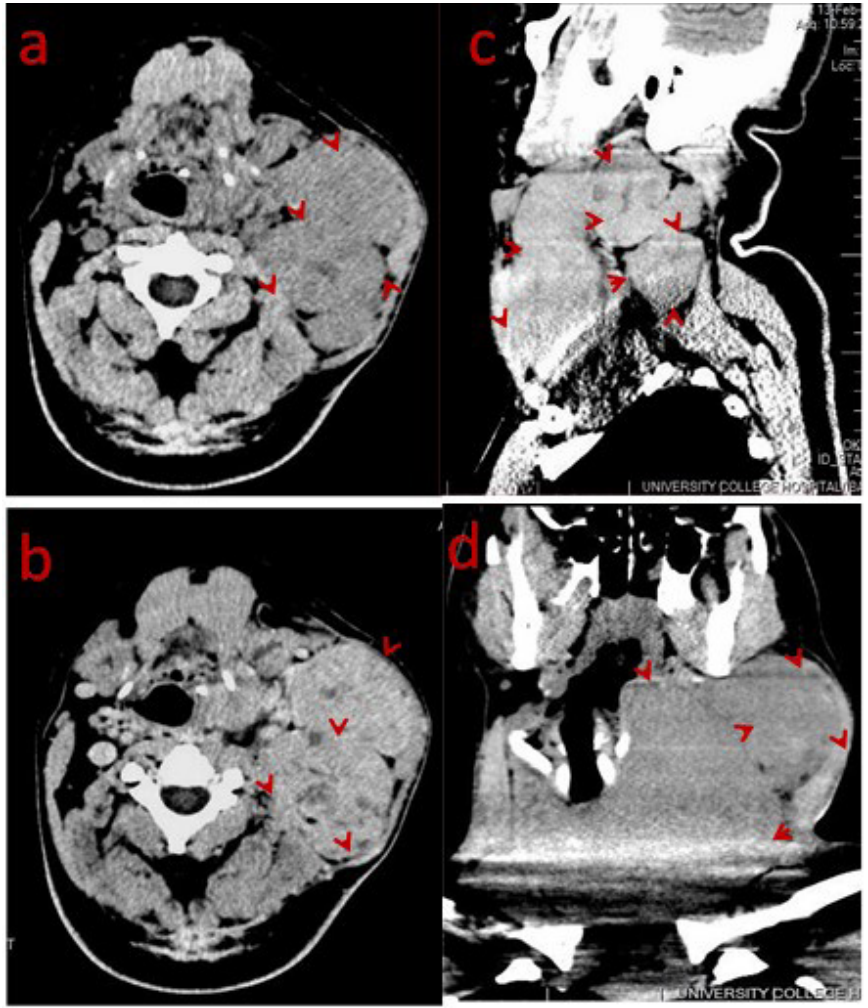

Fig. 1 - CT of the Head and Neck showing multiple enhancing round-oval shaped iso-dense masses with central hypo-densities consistent with enlarged cervical Lymph nodes (Red arrow heads) with necrotic centers in the anterolateral and the left side of the neck demonstrated in

a) Axial view in non-enhanced contrast NECT

b) Axial view in contrast enhanced CECT

c) Sagittal view CECT

d) Coronal view CECT

There is associated medial extension with right sided displacement of the trachea and compression of the laryngeal airway

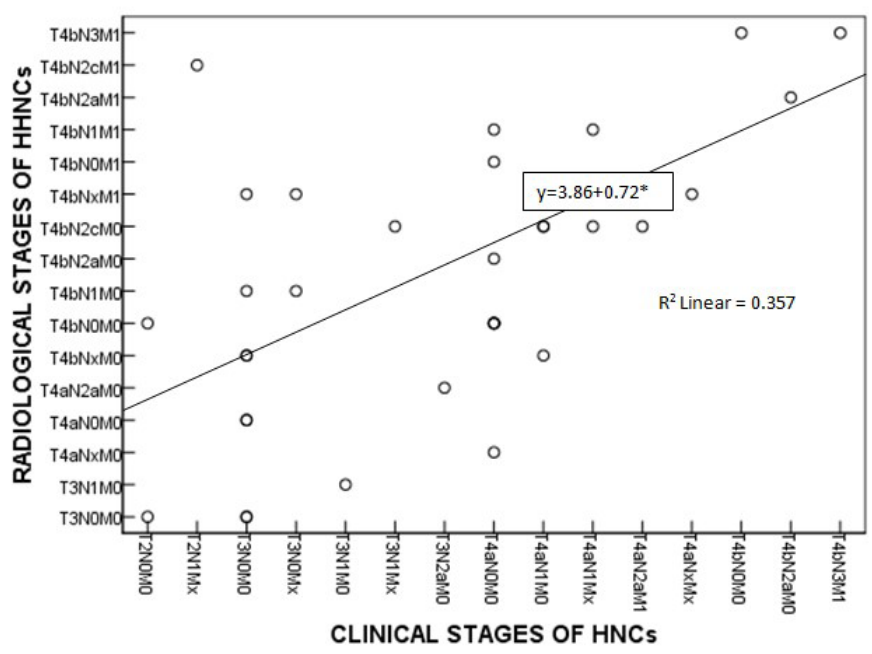

Fig. 2 - Correlation between clinical stages and radiological stages of HNC.

\section{Discussion}

Late stage HNCs clinical presentation (Stages III and IV) is a management challenge with up to $50 \%$ cited in western literature ${ }^{6,18,19}$. In developing countries late stage presentation of up to $90 \%$ in Kenya, $79.1 \%$ in Brazil and $65 \%$ in Thailand ${ }^{20-22}$ have been reported. The findings in this study $(94.2 \%)$ is in keeping with other resource limited economy. Kolude et al. ${ }^{23}$ (2013) attributed the delayed presentation to poverty, lowawareness, poor health seeking attitudes of patients and health care professional delay. The present study went further to sub-classify the clinical tumor cases by utilizing MDCT images for radiological staging.Previous study by Issacs et al. ${ }^{24}$ have shown upgrade of $\mathrm{T} 2$ to $\mathrm{T} 4$ laryngeal carcinoma with deep-spread pattern while Gatenby et al. ${ }^{25}$ reported a series in which CT scan findings altered treatment planning in up to $35 \%$ of patients who presented with $\mathrm{T} 2$ and $\mathrm{T} 3$ stages. The low percentage of upstage in the later study may be partly due to the use of conventional 3-mm slices in axial CT imaging as against the more recent $0.5 \mathrm{~mm}-1 \mathrm{~mm}$ cuts inmultiplanar reconstructed CT imaging employed in this study. Dillon and Hamsberger ${ }^{26}$ in a study of HNCs observed that CT imaging upgraded previous clinical T2 stages to higher grades. Berker ${ }^{27}$ also pointed out the tendency of CT to up-stage malignant tumors in a large number of cases which was validated by Lell et al..$^{10}$ (2008).

In another study by Prehn et al..$^{28}$ (1998) that utilized conventional CT, the majority of the hypopharyngeal tumors were upstaged to T4 but only a minority of oropharyngeal tumors were upstaged to T4. In our study, all hypopharyngeal T2, T3 and T4a clinical tumors were upstaged to $\mathrm{T} 4 \mathrm{~b}$ radiological tumors while the majority of oropharyngeal T3 cases were upstaged to T4a. The higher proportion of upgrade in the present study may be partly due to the predominant advanced stage of cases due to delay in patients' presentation for cancer care; an additional factor may be the use of high resolution MDCT.

It is generally agreed that detection of HNC nodal metastasis is more accurately performed with imaging rather than with clinical palpation, therefore imaging is used in detection of nodal metastasis at presentation and in early detection of nodal tumor recurrence. CT was widely considered to be the gold standard imaging technique for identifying nodal metastasis and extra nodal spread ${ }^{29,30}$. However, MRI provides several advantages like excellent soft-tissue contrast by being able to differentiate normal from pathologic tissues, permits the exact delineation of tumor margins, over $\mathrm{CT}$ in the evaluation of head and neck region tumors. MRI is non-ionizing with multiplanar acquisition and might not require intravenous contrast administration. On the other hand, CT has the advantage of detection of mild bony changes, relatively unaffected by patient motion and other artifacts unlike MRI which is also expensive, unavailable and or inaccessible for HNC patients in most institutions in our setting ${ }^{31}$.

In the index study, it was observed that about $35.2 \%$ of the regional lymph node metastasis was revealed on clinical assessment in contrast with $47.1 \%$ revealed by the CT imaging. The sensitivity (78.9\%), specificity (93.3\%), PPV (93.8\%), NPV $(77.8 \%)$ and accuracy $(85.3 \%)$ indicate that MDCT increased the potential of detecting metastatic cervical lymph nodes, this was evident in 6 cases in which MDCT correctly changed the clinical staging of nodal involvement; clinical nodal stage was upgraded in 5 cases and downgraded in 1 case. Previous works on the efficacy of CT in detecting nodal metastasis in HNCs include those of King et al. ${ }^{29}$, Branstetter et al. ${ }^{32}$ and Anand et al. ${ }^{33}$ The 
sensitivity, specificity, PPV, NPV and accuracy of CT findings inf their studies were: (sensitivity 65\%, 74\% \& 77.5\%); (specificity 93\%, 75\% \&92.4\%); PPV (96\%, 63\% \& 94.5\%); (NPV 50\%, $83 \%$ \& $71 \%$ ); (accuracy $73 \%, 74 \%$ \& $83 \%$ ) respectively. The sensitivity in the present study is within the upper limit of the estimated range of $70-80 \%$ in previous literature, this is possibly due to the use of contrast enhancement and multiplanar reformatted images (as compared to conventional CT imaging techniques). Krestan et al. ${ }^{34}$ stated that the efficacy of CT scans depend on the type of CT machine and other technical abilities such as contrast enhancement. Anand et al. ${ }^{33}$ ascribed differences in the efiicacy and appearances of CT images to several factors such as the use of larger sections of scan, use of different criteria for positive node and use of different bolus or continuous contrast infusion by pump injectors. A contrary opinion by Lell et al. ${ }^{10}$ observed no significant difference between the performance of the recent MDCT (high resolution CT using $0.5-1 \mathrm{~mm}$ cuts) and the older $\mathrm{CT}$ protocols utilized for conventional CT scans with $3 \mathrm{~mm}$ slice thickness for the accurate estimation of nodal mettastsses.

Up to $32.8 \%$ of patients in the study had radiologic stage of M1 in contrast to clinical examination which revealed metastasis of $8.8 \%$. Most reports on HNCs gave $10-20 \%$ prevalence of metastasis in HNCs but de Bree et al..$^{35}$ stated that patients with $\geq 3$ metastatic lymph nodeshave up to a $50 \%$ risk of distance metastasis. Majority of the cases in this study were late stage presentations that may have allowed enough time for multiple nodal involvement and distant metastasis.

Each tumor stage has inherent prognostic importance but of particular importance is the pre-operative prediction of margins of T4 tumor in determining resectability and the optimal extent and duration of such surgery. Staging also provides information on the need for concomitant chemo-radiotherapy Conley ${ }^{36}, 2006$ and Petralia et al. ${ }^{37}$

The implication of alteration of changes from clinical to radiological staging plays a significant role in tumor resectability. Because $\mathrm{n}$ this study, only $23.6 \%$ of stages III and IVa were resectable against the suggestion of $91.2 \%$ (stages II,III and IVa) by clinical staging. Furthermore, a sizeable proportion of clinically resectable tumors turned out to be radiologically advanced unresectable tumors. Many of the cases in this study later required adjuvant surgery and chemo-radiotherapy (44.1\%). In addition, a considerable proportion were inoperable and only benefited from palliative care $(32.4 \%)$.

Early diagnosis is the most important determining factor for improving HNCs with up to $80-90 \%$ survival rate stated for stages $\mathrm{IHNCs}^{3}$. In developed countries, recent imaging investigation and evaluation of HNCs involve the use of 5'Fluro-deoxyglucose FDG-PET/CT with supportive MRI or ultrasound as adjuncts. Despite these facilities, $\sim 50 \%$ of patients diagnosed with cancer die of advanced disease. Indeveloping countries; this figure reaches up to $80 \%$. By the year 2020, WHO estimates that $70 \%$ of new cancer cases will be in developing countries, with most patients presenting with late stages of cancer, even when patient seek early care, diagnosis and treatment may be delayed, unaffordable, or unavailable ${ }^{38}$.

Branstteter et al..$^{32}$ compared PET scan, MDCT and PET-CT scan, and observed that the proportion of extra lesions identified were $21 \%, 37 \%$ and $40 \%$ respectively which suggests better detection and evaluation of MDCT than PET scan alone and a very close sensitivity of MDCT compared withd PET-CT scan. PET and MRI as imaging modalities have been available for over 30 years. Inspired by the PET-CT combination, over 50 PET-MRI machines have been developed and utilised in the USA and European countries. , Though a hybrid form of imaging with promising clinical applications, it has not yet been established as an imaging modality for clinical practice ${ }^{39}$.

The findings in this study show the superiority of MDCT imaging compared with clinical physical examination in staging of patients with HNCs and it is in agreement with Shah et al. ${ }^{40}$ (2008) who stated that MDCT should be the first diagnostic imaging study for patients with head and neck cancers particularly with suspected oropharyngeal and/or laryngeal involvement. Therefore, we recommend MDCT as the first line image investigation for HNCs in low economic resource setting where PET-CT may not be available.

In conclusion MDCT was significantly more accurate than clinical examination in the determination of tumor size, nodal involvement and tumor metastasis of HNCs according to the AJCC/UICC TNM guidelines. Authors recommend MDCT as first line imaging technique in the evaluation of HNCs in resource limited settings.

\section{References}

1. Shishodia NP, Divakar DD, Al Kheraif AA, Ramakrishnaiah R, Pathan AA, Parine NR, et al. End stage palliative care of head and neck cancer: a case study. Asian Pac J Cancer Prev. 2015;16(3):1255-8.

2. Chin D, Boyle GM, Porceddu S, Theile DR, Parsons PG, Coman WB. Head and neck cancer: past, present and future. Expert Rev Anticancer Ther. 2006 Jul;6(7):1111-8.

3. Lam DK, Schmidt BL. Orofacial pain onset predicts transition to head and neck cancer. Pain. 2011 May;152(5):1206-9. doi: 10.1016/j. pain.2011.02.009.

4. Brockstein B, Haraf DJ, Rademaker AW, Kies MS, Stenson KM, Rosen F. et al. Patterns of failure, prognostic factors and survival in loco regionally advanced head and neck cancer treated with concomitant chemo radiotherapy: a 9-year, 337-patient, multi-institutional experience. Ann Oncol. 2004 Aug;15(8):1179-86.

5. Worsham MJ. Identifying the risk factors for late stage head and neck cancer. Expert Rev Anticancer Ther. 2011 Sep;11(9):1321-5. doi: 10.1586/era.11.135.

6. Lopez-jornet P, Camacho-Alomso F: New barriers in Oral Cancer. Patient accessibility to dental examination-A pilot Study. Oral Oncol. 2006 Nov;42(10):1022-5.

7. McCabe KJ, Rubinstein D: Advances in Head and Neck Imaging. Otolaryngol Clin North Am. 2005 Apr;38(2):307-19, vii.

8. Forghani R, Yu E, Levental M, Som PM, and Curtin HD: Imaging evaluation of lymphadenopathy and patterns of lymph node spread in head and neck cancer. Expert Rev Anticancer Ther. 2015 Feb;15(2):20724. doi: 10.1586/14737140.2015.978862.

9. Agarwal V, Branstetter IV BF, Johnson JT, Indications for PET/CT in the Head and Neck. Otolaryngol Clin North Am. 2008 Feb;41(1):23-49, v. doi: 10.1016/j.otc.2007.10.005.

10. Lell MM, Gmelin C, Panknin C, Eckel KT, Schmid M, Bautz WA, et al. Thin-Slice MDCT of the Neck: Impact on Cancer Staging. AJR Am J Roentgenol. 2008 Mar;190(3):785-9. doi: 10.2214/AJR.07.3081. 
11. Hsu WC, Loevner LA, Karpati R, et al. Accuracy of magnetic resonance imaging in predicting absence of fixation of head and neck cancer to the prevertebral space. Head Neck. 2005 Feb;27(2):95-100.

12. Lell MM, Greess H, Hothorn T, Janka R, Bautz WA, Baum U. Multiplanar functional imaging of the larynx and hypopharynx with multi-slice spiral CT. Eur Radiol. 2004 Dec;14(12):2198-205.

13. Barnes L, Eveson J, Reichart P, Sidransky D, editors. World health organization classification of tumors. Pathology and genetics of head and neck tumors. Lyon: IARC Press; 2005.

14. Greene FL, Page DL, Fleming ID, Fritz AG, Balch C, Haller DG, et al., editors. The American Joint Committee on Cancer Staging Manual. 6th. New York: Springer; 2002.

15. Fleming ID, Cooper JS, Henson DE, Hutter RVP, Kennedy BJ, Murphy GP, et al., editors. AJCC cancer staging manual. 5th ed. Philadelphia: Lippincott-Raven; 1997. 294p.

16. Madison MT, MD, Remley KB, Richard MD. Radiologic diagnosis and staging of head and neck squamous cell carcinoma. Otolarygol Clin North Am. 1998 Aug;31(4):727-54.

17. Fritz A, Percy C, JackA, Shanmugaratmam K, Sobin L, arkin DM, et al. editors. International Classification of Diseases for Oncology (ICD-O). 3rd ed. Geneva: WHO; 2000.

18. Zong. J, Lin S, Lin. J, Tang L, Chen B, Zhang M, et al. Impact of intensitymodulated radiotherapy on nasopharyngeal carcinoma: Validation of the 7th edition AJCC staging system. Oral Oncol. 2015 Mar;51(3):254-9. doi: 10.1016/j.oraloncology.2014.10.012.

19. Warnakulasuriya $S$. Global epidemiology of oral and oro-pharyngeal cancer. Oral Oncol. 2009 Apr-May;45(4-5):309-16. doi: 10.1016/j. oraloncology.2008.06.002.

20. Onyango JF, Awange DO, Njiru A, Macharia IM. Pattern of occurrence of head and neck cancer presenting at Kenyatta National Hospital, Nairobi. East Afr Med J. 2006 May;83(5):288-91.

21. Carvalho AL, Pintos J, Schlecht NF, Oliveira BV, Fava SA, Curado MP, et al. Predictive factors for diagnosis of advanced-Stage squamous Cell carcinoma of the Head and Neck. Arch otolaryngol Head Neck Surg. 2002 Mar;128(3):313-8.

22. Kerdpon D, Sriplung $H$. Factors related to delay in diagnosis of oral squamous cell carcinoma in southern Thailand. Oral Oncol. 2001 Feb;37(2):127-31.

23. Kolude B, Adisa A, Adeyemi B, Lawal A. Stages of delay in Oral cancer care evaluated at a tertiary health centre. Afr. J.Med.med Sci. 2013 Dec;42(4):347-53.

24. Issacs JJ, Mancuso AA, Mendenhall WM, Parsons JT. Deep spread patterns in CT staging of T2-4 squamous cell laryngeal carcinoma. Otolaryngol Head Neck Surg. 1988 Nov;99(5):455-64.

25. Gatenby RA, Mulhern CB, Strawitz J, Moldofsky PJ. Comparison of clinical and CT staging of head and neck tumors. AJNR Am J Neuroradiol. 1985 May-Jun;6(3):399-401.
26. Dillon WP, Harnsberger HR. The impact of radiologic imaging on staging of cancer of the head and neck. Semin Oncol.1991 Apr;18(2):64-79.

27. Berker M. Neoplastic invasion of laryngeal cartilage: radiologic diagnosis and therapeutic implications. Eur. J Radiol. 2000 Mar;33(3):216-29.

28. Prehn RB, Pasic TR, Harari PM, Brown WD, Ford CN. Influence of computed tomography on pre-therapeutic tumor staging in head and neck cancer patients. Otolaryngol Head Neck Surg. 1998 Dec;119(6): 628-33.

29. King AD, Tse GM, Yuen EH, To EW, Vlantis AC, Zee B, et al. Comparison of $C T$ and MR imaging for the detection of extra-nodal neoplastic spread in metastatic neck nodes. Eur J Radiol. 2004 Dec;52(3):264-70.

30. Sakai O, Curtin HD, Romo LV, Som PM. Lymph node pathology. Benign proliferative. Radiol Clin N Am. 2000 Sep;38(5):979-98.

31. Dillon WP. Magnetic resonance imaging of head and neck tumors. Cardiovasc Intervent Radiol. 1986;8(5-6):275-82.

32. Branstetter BF, Blodgett TM, Zimmer LA, Snyderman CH, Johnson JT, Raman S, et al. Head and Neck Malignancy: Is PET/CT More Accurate than PET or CT Alone? Radiology. 2005 May;235(2):580-6.

33. Anand N, Chaudhary N, Mittal M.K, Prasad R. Comparison of the efficacy of clinical examination, ultrasound neck and computed tomography in detection and staging of cervical lymph node metastasis in head and neck cancers. Indian J Otolaryngol Head Neck Surg. 2007 Mar;59(1):19-23. doi: 10.1007/s12070-007-0005-6.

34. Krestan C, Herneth AM, Formanek M, Czerny C. Modern imaging lymph node staging of the Head and Neck region. Eur J Radiol. 2006 Jun;58(3):360-6.

35. de Bree R, Deurloo EE, Snow GB, Leemans CR. Screening for distant metastasis in patients with head and neck cancer. Laryngoscope. 2000 Mar;110(3 Pt1):397-401.

36. Conley BA. Treatment of advanced head and neck cancer: what lessons have we learned? J Clin Oncol. 2006 Mar;24(7):1023-5.

37. Petralia G, Preda L, Giugliano G, Jereczek-Fossa BA, Rocca A, D'Andrea $G$, et al. Perfusion computed tomography for monitoring induction chemotherapy with squamous cell carcinoma of the upper aero digestive tract: correlation between changes in tumor perfusion and tumor volume. J Comput Assist Tomogr. 2009 Jul-Aug;33(4):552-9. doi: 10.1097/RCT.0b013e31818d446e.

38. Soyannwo SO. How to make a difference in the Developing World: Organizing Resources. In: Paice JA, Bell RF, Kalso EA, Soyannwo OA., editors. Cancer Pain from Molecules to suffering. IASP Press; 2010. p.333-45.

39. Nensa F,Beiderwellen K, Heusch P, Wette A. Clinical applications of PET/MRI: current status and future Perspectives. Diagn Interv Radiol. 2014 Sep-Oct;20(5):438-47. doi: 10.5152/dir.2014.14008.

40. Shah GV, Wesolowski JR, Ansari SA, Mukherji SK. New directions in head and neck imaging. J Surg Oncol. 2008 Jun 15;97(8):644-8. doi: $10.1002 / j s 0.21022$. 